\title{
Psychological predictors of formation and development of personal identity of older preschool children
}

\author{
Liubov Pomytkina ${ }^{*}$, Ruslana Moroz ${ }^{2}$, Oleksandr Kovalchuk ${ }^{3}$, and Eduard Pomytkin ${ }^{4}$ \\ ${ }^{1}$ National Aviation University, ave. Liubomyra Huzara, 1, 03058, Kyiv, Ukraine \\ ${ }^{2}$ Methodological Center for Practical Psychology and Social Work of the National Academy of \\ Pedagogical Sciences of Ukraine, shose Chapaevske, 98, 03045, Kyiv, Ukraine \\ ${ }^{3}$ National Defence University of Ukraine named after Ivan Cherniakhovskyi, ave. Povitroflotskyi, 28, \\ 03049, Kyiv, Ukraine \\ ${ }^{4}$ Ivan Ziazun Institute of Pedagogical and Adult Education of the National Academy of Pedagogical \\ Sciences of Ukraine, str. Maxim Berlinsky, 9, 04060, Kyiv, Ukraine
}

\begin{abstract}
The article presents the results of the study to determine the predictors of the formation and development of personal identity of older preschool children. The conceptual basis of the study is the assumption that the formation of triangulatory relations internalized in the personality structure of maternal and paternal objects is an important prerequisite for the development of a holistic, stable, differentiated personality. The purpose: to highlight the results of empirical analysis of features and to determine the factors of formation and development of personal identity of older preschool children.

Methods: biographical, semi-structured interview, analysis of family narratives; test of M. Kuhn and T. McPartland "Who I am?", "Three trees", "Compose a fairy tale"; H. Olson, J. Portner, I. Lavi "FASES-3", "Interaction of parents and the child" of I. Markovska; E. Eidemiller's "Analysis of Family Interaction"; "Scale of rejection of the child in the family" of A. Barkan; content analysis; methods of mathematical statistics SPSS-17. As a result of a factor analysis parameters of the family system, identification with the maternal or paternal object, four factors were identified: ability to triangulatory relations, stability/instability of personal identity of older preschool children, neutral selfattitude, factor of prerequisites for the formation of personal identity.

Thus, in the course of the study it was determined that the formation of personal identity of a child of older preschool age is determined by the correlation between the place that the child occupies in the system of human relationships, and above all in the system of family relationships, and psychological features which have already been formed.
\end{abstract}

\footnotetext{
* Corresponding author: Lyubvit@ukr.net
} 


\section{Introduction}

At different times, research on the development of the child's personality took place in accordance with the socio-political and economic situation, ideological accents, scientific priorities of researchers. The relevance of the study is due to the rapid change of paradigms and processes occurring in the XXI century. Such transformations cannot but affect the living environment, which plays a leading role in the development of a child's personal identity.

Formation and development of identity is a way of gradual integration of one's own experience, generalized experiences, cognitive structures into a holistic system of subjective reality, which correlates with objective reality. Identity is formed and developed as a dynamic structure under the influence of individual and social dimensions. Therefore, it is impossible to study the manifestations of personal identity without taking into account the real life context in which it is carried out.

The main determinants of a child's personal identity are social connections (Miller \& Mangelsdorf, 2005) [1] and interactive relationships with other significant people, especially parents (Cox \& Paley, 1997; Clark \& Symons, 2000; Moroz, 2013) [2-4]. Competent parental functioning directly or indirectly affects the individual psychological well-being of the child (Belsky, 1984; Pomytkina and et., 2019) [5, 6].

Studies in the field of attachment theory show that a child is born with the need for attachment and social contact (Bowlby, 1969; Crittenden , 1990; Davies \& Cummings, 1994, Verschueren, Marcoen, Schoefs, 1996) [7-9]. According to Bowlby, the working model of "I" is constituted due to the early interaction between the significant figure and the infant, and the constructed "internal working model" determines self-understanding and future expectations of close relationships (Sroufe, 1985; Bretherton, 1991) [10].

According to the quality of living in marriage and the style of emotional attachment of the mother, the child develops a leading style of emotional attachment, which is later represented in interpersonal interaction throughout life (Doyle, Markiewicz, Brendgen, Lieberman \& Voss, 2005) [11]. The emotional development of children with different types of emotional attachment takes place along different trajectories (Kochanska, 2003) [12], due to the child's attachment to the mother the self-image is formed (Cassidy, 1988) [13].

The concept of "identity" is concretized as a firmly mastered and personally perceived image of oneself; a sense of stable mastery of the personality's own "I", regardless of changes in "I" in time and space; ability to adequately solve tasks that arise at each stage of development. At the personality level, this is expressed in stable human perceptions of their own characteristics of the personality, the degree of self-worth, self-esteem, which is formed in the child during the process of its socialization (Moroz, 2010) [14].

There is reason to believe that preschool age is a fundamental age for the formation of self-esteem and self-understanding: there is an integration (interiorization) of self-image, based on the image of parents about themselves (Damon \& Hart, 1982; Eder, 1990; Marsh, 2002, 2004; Brown, 2008) [15-19]. The formation of personal identity in preschoolers is the result of the child's interaction and identification with parents, and the internalized image of "I". The theory of object relations states that the transition from symbiotic to dyadic, and from bilateral to tripartite relations with the appearance of the third object, and the implementation of the process of "early" triangulation are prerequisites for the transition to the oedipal stage of development (Winnicott, 1987) [20].

We assume that a mature, stable personal identity is characterized by the ability to personal object relations with the inclusion of a "third object". The ability to triangulate leads to the formation of an objective perception of reality, to the formation of a strong identity. In the context of the study, we will talk about the representation of the image of "I" as a result of identifications with parental objects, the ability to triangulate, which means 
the ability of personal object relations and to be an object for oneself, and various images of "I" as components of personal identity of the child - physical, active, material, social, reflexive, "I"-in the past, "I"-in the future, "I"-in the present and so on.

This study conceptualizes the personal identity of an older preschool child through the representation in the social environment of the experiences of "self-image" and ideas about oneself.

The purpose of the article: to highlight the results of empirical analysis of features and to determine the factors of formation and development of personal identity of older preschool children.

Research hypothesis: the ability to triangulatory relations in the structure of the child's personality and the presence of internalized maternal and paternal objects in the personality structure are predictors of the formation and development of a holistic, stable, differentiated personality.

\section{Methods}

The study involved 68 older preschool children (from 4.5 to 7 years) and 68 their parents. Theoretical and empirical research methods were used, namely: narrative, biographical, semi-structured interview, structural and functional analysis of family narratives; methods of research of personal identity of children of older preschool age: observation, conversation, test of M. Kuhn and T. McPartland "Who I am?", projective methods "Three trees", "Compose a fairy tale"; parameters research methods of family system, features of parent-child interaction, perception of the child by parents: methods of H. Olson, J. Portner, I. Lavi "FASES-3", "Interaction of parents and the child" of I. Markovska; E. Eidemiller's "Analysis of Family Interaction"; "Scale of rejection of the child in the family" of A. Barkan; content analysis; methods of mathematical statistics for quantitative and qualitative processing of the obtained data using the statistical package SPSS-17 by the method of Principal components.

The following were studied:

1) manifestations and quality of the child's identity: integrity, stability, instability, differentiation/non-differentiation of the image of "I", the formation/non-formation of the child's triangulatory relationship, identification with the father, mother object or other figure in the family, structural components of identity (physical, activity, material, social, reflexive, "I"-in the past, "I"-in the future, "I"-in the present), the child's representation of the image of "I" from the standpoint of the father or mother, positive, negative or neutral self-attitude from the words of the father or mother, a sense of own significance, the need for recognition;

2) features of parent-child relationships in the child's perception: emotional distance from parents, favorable family relationships, feelings of emotional acceptance/rejection, rejection in the family, emotional dependence, emotional attitude towards each parent or other family members, authority of father or mother in the family.

\section{Results}

In order to determine the main factors that characterize the peculiarities of the formation of personal identity of older preschool children, a factor analysis of the obtained data on the manifestation of these phenomena was performed. As a result of factor analysis, four factors were identified, the share of the total variance is $61.41 \%$ (Table 1 ).

Summarizing the results of qualitative and quantitative analysis of the data on the manifestations of personal identity of older preschool children, we concluded that by the 
level and quality of personal identity of older preschool children who participated in the study, we can distinguish four groups (Figure 1).

Table 1. Factor analysis of the manifestations of personal identity of older preschool children and features of parent-child relationships in the perception of the child

\begin{tabular}{|c|c|c|c|c|}
\hline The total weight of the factor & 20.1 & 16.5 & 13.2 & 11.6 \\
\hline \% explanatory variance & 16.9 & 15.1 & 13.9 & 12.8 \\
\hline \% of accumulated dispersion & 16.9 & 27.6 & 54.1 & 61.4 \\
\hline & 1 & 2 & 3 & 4 \\
\hline Ability to triangulatory relations & -0.87 & & & -0.52 \\
\hline Lack of triad relationships in the figure & $\mathbf{0 . 8 7}$ & & & \\
\hline The child's sense of favorable family relationships & -0.86 & & & -0.49 \\
\hline Emotional distance from parents is absent & -0.58 & -0.34 & & \\
\hline Emotional distance with parents & 0.54 & & & \\
\hline Emotional distance of the boy from father & -0.54 & & & \\
\hline Emotional distance of the girl from mother & -0.5 & & 0.34 & \\
\hline Violation of the identification mechanism & 0.52 & 0.34 & & \\
\hline Relationships are broken, negative emotions towards the father & 0.46 & & & \\
\hline Emotional distance with all family members & -0.44 & 0.31 & 0.32 & \\
\hline Integral, qualitatively stable image of "I" & & -0.86 & & -0.42 \\
\hline Qualitatively unstable, diffuse identity & -0.36 & 0.86 & & \\
\hline Differentiation of the image of "I": differentiated, multicomponent image of I & & -0.76 & & -0.38 \\
\hline Differentiation of the self-image: undifferentiated self-image & -0.35 & 0.76 & 0.34 & \\
\hline Emotional distance from mother & -0.46 & 0.74 & & \\
\hline Dominance of the parent over the child & & -0.72 & & \\
\hline Valence of identity: negative, problems of identification & & 0.68 & & \\
\hline Disturbed relationships, negative emotions towards the mother & & 0.66 & & 0.32 \\
\hline Identity structure: the predominance of the activity "I" & & $\mathbf{0 . 5 7}$ & & \\
\hline Identity structure: the predominance of the material "I" & & $\mathbf{0 . 5 5}$ & & \\
\hline Identification of the boy with father & & -0.44 & & \\
\hline $\begin{array}{l}\text { Assessment of personality by parents: a positive image from the words of the } \\
\text { father }\end{array}$ & & -0.38 & & -0.64 \\
\hline Identification of the boy with mother & & 0.38 & & \\
\hline $\begin{array}{l}\text { Assessment of personality by parents: a negative image from the words of the } \\
\text { father }\end{array}$ & & 0.38 & 0.55 & \\
\hline Identity structure: the predominance of the reflexive "I" & -0.38 & -0.36 & & -0.33 \\
\hline $\begin{array}{l}\text { Assessment of personality by parents: a negative image from the words of the } \\
\text { mother }\end{array}$ & & 0.36 & 0.35 & \\
\hline Identity valence: neutral & & & 0.79 & 0.38 \\
\hline Identification with another family member & & & $\mathbf{0 . 7 2}$ & \\
\hline A sense of significance, the need for recognition & 0.36 & & 0.68 & 0.32 \\
\hline No signs of dominance & & & $\mathbf{0 . 5 8}$ & \\
\hline Identity structure: unexpressed structure & & 0.36 & $\mathbf{0 . 5 1}$ & \\
\hline Identity structure: the predominance of the social component & & & 0.5 & \\
\hline Dominance of another family member & & & 0.48 & \\
\hline Identity valence: positive & & & -0.44 & -0.46 \\
\hline Assessment of child by parents: a neutral image of "I" from the words of the father & & 0.35 & $\mathbf{0 . 3 8}$ & \\
\hline $\begin{array}{l}\text { Assessment of child by parents: a neutral image of "I" from the words of the } \\
\text { mother }\end{array}$ & -0.56 & 0.35 & 0.36 & \\
\hline No signs of identity violation & -0.47 & -0.34 & & -0.78 \\
\hline $\begin{array}{l}\text { Dissatisfaction with family relationships in general, aggressive tendencies towards } \\
\text { family members }\end{array}$ & & & & 0.76 \\
\hline $\begin{array}{l}\text { Assessment of child by parents: a positive image of "I" from the words of the } \\
\text { mother }\end{array}$ & & & & -0.72 \\
\hline Identification of the girl with mother & & & & -0.67 \\
\hline Equal authority of father and mother & & & & -0.58 \\
\hline Feelings of emotional rejection in the family, emotional dependence & 0.64 & & & 0.54 \\
\hline Identity structure: the predominance of the physical "I" & & & & 0.51 \\
\hline Identification of the girl with father & & & & 0.48 \\
\hline
\end{tabular}


The identified groups of children were confirmed by the results of statistical analysis according to Pearson's $\chi 2$-criterion and have statistical differences in indicators: the ability to triangulate (according to Pearson's $\chi 2$-criterion, the significance reaches the level of $\mathrm{p} \leq$ $0.001)$; integral, stable image of "I" ( $\mathrm{p} \leq 0.01)$; qualitatively unstable, diffuse image of "I" $(\mathrm{p} \leq 0.001)$; differentiated image of "I" $(\mathrm{p} \leq 0.001)$; the predominance of the social "I" in the identity structure $(\mathrm{p} \leq 0.005)$; the predominance of the physical "I" ( $\leq \leq 0.005)$; predominance of the activity "I" $(\mathrm{p} \leq 0.005)$; the predominance of the material "I" ( $\mathrm{p} \leq$ $0.005)$; the predominance of the reflexive "I" $(\mathrm{p} \leq 0.005)$.

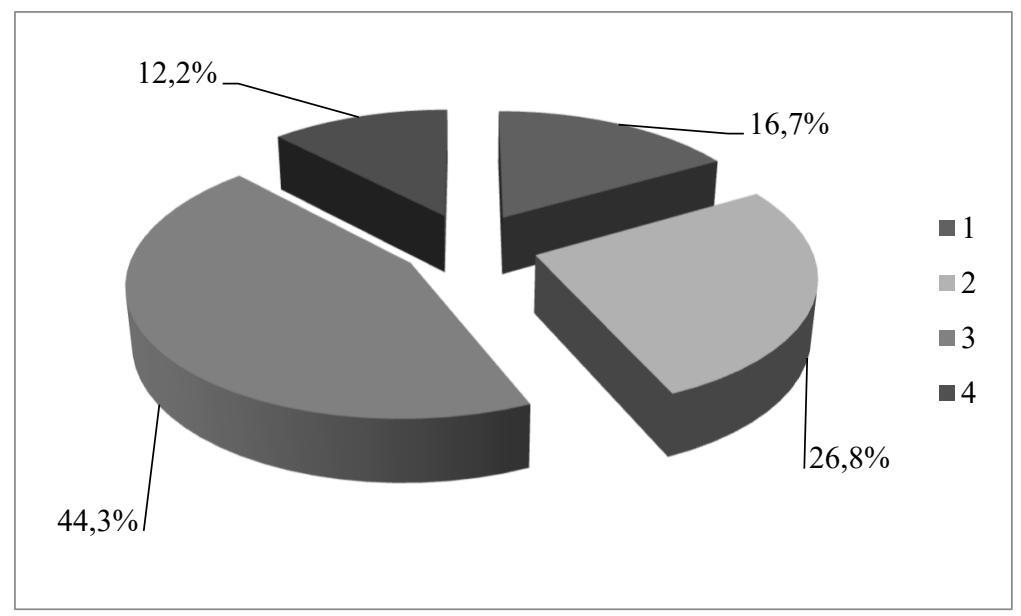

Fig. 1. Distribution of older preschool children by manifestations of personal identity.

The results of the experimental study data of the manifestations of personal identity of older preschool children make it possible to state:

1. Integrity, stability of personal identity of a child of older preschool age is characterized by structure, differentiation, lack of negative self-esteem, may depend on a positive attitude, approval of the father provided that he has authority in the family, combined with no violations in the child's relationship with mother, excessive strictness of parents to the child and favorable for the child family atmosphere in general, the ability to triangulatory relationships; internalization of maternal and paternal objects. The structure of a holistic personal identity is dominated by a reflexive component.

2. It is established that qualitatively unstable, undifferentiated personal identity in older preschool children can develop in the absence of parental authority in the family, the presence of disturbed emotional relationships with parents, in particular with the mother, hyperprotection in upbringing, excessive control over the child, conditional love for the child, parents' lack of confidence in upbringing.

3. It is determined that the diffuse, unexpressed structure of personal identity can be caused by a neutral, invaluable attitude to the child, which means the least positive attitude of the personality and is a compensatory or protective form of unpleasant emotional states. Other factors that contribute to the formation of an indeterminate structure of personal identity - indefinite, inconsistent, emotionless assessment of personality by father and mother, the child's rejection in perception of parents as authoritative figures, the dominance of another family member.

4. The absence of violations in the development of personal identity of older preschool children is evidenced by the child's representation of own positive image of "I", transmitted by mother and father, identification of the girl with mother, the child's sense of favorable family atmosphere, ability to triangulatory relationships, positive attitude of the child. 
Violation of the development of personal identity may be evidenced by the presence of a child's sense of emotional rejection by the family, dissatisfaction with family relationships in general, aggressive emotions towards family members, relationship disorders with the mother, the need for recognition, self-affirmation of the child, emotional dependence on the object.

It is established that the formation of a holistic, stable, structured personal identity of older preschool children is due to the child's ability to triangulatory relationships, the presence of internalized in the personality structure of maternal and paternal figures, a positive attitude of the father in the presence of his authority in the family and no violations in relationships with the mother, as well as a favorable family atmosphere in the family.

It was found that the development of diffuse, unexpressed structure of personal identity may be due to uncertain, inconsistent or emotionless attitude of parents to the child, the dominance of another family member, the rejection of parents as authoritative figures. As a result, the child develops a neutral, indefinite self-attitude as a compensatory or protective form of unpleasant emotional states.

It is determined that the absence of violations in the development of personal identity of older preschool children is evidenced by: the child's representation of own positive image of "I", transmitted by parents, the ability to triangulatory relationships, identification of the girl with mother, the child's feelings of a positive family atmosphere. There is a connection between the manifestations of disorders in the development of personal identity of older preschool children and the child's feelings of emotional rejection in the family, dissatisfaction with family relationships, the presence of aggressive emotions towards family members, disturbed relationships with the mother, the need in recognition, selfaffirmation of the child, emotional dependence on the object.

According to the quality of personal identity of older preschool children in the surveyed sample, four groups were identified:

1) with a high level of personal identity, characterized by the ability to triangulatory relations, prerequisites for the development of a holistic, stable personal identity, certainty of gender role functions, a high level of identity differentiation, the structure of which is dominated by social and prerequisites for the development of reflexive components;

2) the level of formation and quality of personal identity is above average, which is characterized by positive self-esteem, integrity, a certain structure, with a predominance of activity and social components in the structure of identity;

3 ) the level of formation of personal identity below average, with ambivalent or neutral self-attitude, with a qualitatively unstable, diffuse image of "I", with a predominance of activity and physical components in the structure of personal identity;

4) indefinite, diffuse personal identity, undifferentiated image of "I", with a predominance of material and physical components in the structure of personal identity.

\section{Discussion}

Thus, the results of the conducted study on the problem of identifying factors of formation and development of personal identity of older preschool children, suggest that one of the most important factors in the development of mature, stable personal identity is the ability to triangulatory relationships.

According to the theory of object relations, the ability of a preschooler to have a triangulatory relationship means the child's ability to have a simultaneous relationship with two people. In the child's attitude to father and mother, as well as to their relationship with each other, the structure of personal identity as a divided unity is stabilized. Until the stage of the formed triangulation, the role of the main object, which determines the emotional atmosphere of bilateral relations, is performed by the mother. Triangulation causes internal 
release from the mother and subsequent entry into Oedipal triangulation, which is characterized by a certain emotional detachment of a boy with his father (-0.54) and of a girl with her mother (-0.5). During the experience of Oedipal conflict, according to psychoanalytic theories, a girl feels inferior to a powerful mother, and a boy - to his father. However, the ability to triangulate is possible only in the presence of emotional acceptance by parents, a feeling of favorable family atmosphere, which includes, among other manifestations, mature sexual and personal relationships between spouses, as well as the absence of disturbances in the relationship with the father and emotional distance between parents and child. Neutral, invaluable attitude of the father to the child's personality, in contrast to the maternal unconditional acceptance, as well as a certain separation from all family members, in our opinion, can also be one of the prerequisites for the formation of the ability to triangulatory relations.

The results of the conducted study suggest that children with unstable identities may have interpersonal disorders and lack of warm, trusting relationship with the mother, which is reflected in the psychological distance. The presence of variables in this factor "Negative image of "I" according to the father's words" and "Negative image of "I" according to the mother's words" together with the variable "Lack of emotional intimacy with the mother" may indicate a direct impact of these factors on the formation of negative self-esteem of the child. In such an emotional family atmosphere, a child may feel psychologically unprotected and vulnerable. Children with a violation in a formation of personal identity are not able to exercise emotional self-regulation, to interact harmoniously with themselves and, as a consequence, with the outside world. In the future, the child may develop a qualitatively unstable, diffuse identity, with an undifferentiated structure, with a predominance of material interests and activities that do not require special willpower.

Identification with the maternal object also does not contribute to the development of a qualitatively stable and integral image of "I" in boys. Gender role identity is formed on the basis of interaction between parents and the child from birth, as well as a sense of muscularity and femininity of parents and the style of their interaction with each other. The initial identification of a boy with a maternal object may result in a female-directed pattern of conscious and unconscious interactions with other people.

Based on the fact that the norm for preschool age is an overestimated self-esteem and a positive attitude towards oneself, a neutral self-attitude towards one's personality, which was revealed during the experiment, can mean only the least positive attitude towards oneself based on a neutral, i.e. undefined or inconsistent evaluation of father and mother, and to determine the formation of an unexpressed, diffuse structure of personal identity in the child. Upon receipt of information that threatens a positive self-image, or lack of positive reinforcement from parents, the protective mechanisms of the personality can be aimed at rationalization, creating an image of false Self, i.e. Ego protects the personality as a whole from the threat, seeks to get rid of unpleasant emotional states and forms protective mechanisms. "Neutrality" of self-attitude of older preschool children is the result of such protective mechanisms as displacement, denial, projection. The natural need of the individual for a positive attitude and self-attitude causes the child a compensatory need for recognition, a sense of their importance, which is realized in the social component in the structure of identity. If the family does not have a clear structure with internal boundaries between the subsystems and the hierarchy of intrafamily roles, i.e. the child's perception shows no signs of dominance of one member of the nuclear family, and the presence of dominance of another family member, the child may have a process of identification with another family member.

The factor of neutral self-attitude of a child of older preschool age can be interpreted as a form of psychological protection in a family with an uncertain structure of intrafamily roles and in the presence of indefinite or inconsistent attitude of parents to the child. 


\section{Conclusions}

The results of the factor analysis determined the predictors of the formation and development of personal identity of older preschool children: the ability to triangulatory relations, stability/instability of personal identity of older preschool children, neutral selfattitude, a factor in the prerequisites for personal identity formation. These factors allow us to state that the child's perception of parental attitude, the modality of assessing own personality, various forms and manifestations of intrafamily interaction may be factors in the formation of personal identity of older preschool children.

There were 4 groups of children who differ from each other at a statistically significant level according to Pearson's $\chi 2$-criterion (significance reaches the levels of $p \leq 0.001$ and $p$ $\leq 0.01$ ) according to the degree of "well-being" of personal identity - from positive, stable, to unfavorable, unstable or distorted.

Thus, in the course of the study it was determined that the formation of personal identity of a child of older preschool age is determined by the correlation between the place that the child occupies in the system of human relationships, and above all in the system of family relationships, and psychological features which have already been formed.

\section{References}

1. P.J. Miller, S.C. Mangelsdorf, Developing selves are meaning-making selves: Recouping the social in self-development. New Directions in Child and Adolescent Development. 109:51-59 (2005) [PubMed] [Google Scholar]

2. M.J. Cox, B. Paley, Families as systems. Annual Review of Psychology. 48:243-267 (1997) [PubMed] [Google Scholar]

3. S.E. Clark, D.K. Symons, A longitudinal study of Q-sort attachment security and self-processes at age 5. Infant and Child Development. 9:91-104 (2000) [Google Scholar]

4. Moroz, R.A. Batkivsko-dytiachi vzaiemyny i rozvytok osobystosti dytyny starshoho doshkilnoho viku. Aktualni problemy psykholohii: Zbirnyk naukovykh prats Instytutu psykholohii imeni H.S. Kostiuka NAPN Ukrainy. K.: «Sribna khvylia». Tom IV. Psykholohiia rozvytku doshkilnyka. V. 9. 198-213 (2013)

5. J. Belsky, The determinants of parenting: A process model. Child Development, 55: 83-96 (1984) [PubMed] [Google Scholar]

6. L. Pomytkina, L. Moskalyova, Y. Podkopaieva, S. Gurov, S. Podplota, V. Zlahodukh. Empirical studies of socio-psychological conditions of formation of ideas about the spiritual ideal in primary school children, International Journal of Children's Spirituality, 24:4, 371-388 (2019) SCOPUS DOI: https://doi.org/10.1080/1364436X.2019.1672626

7. J. Bowlby, Attachment and loss. Vol. 1: Attachment. New York: Basic Books (1969) [Google Scholar].

8. P.T. Davies, E.M. Cummings, Marital conflict and child adjustment: An emotional security hypothesis. Psychological Bulletin. 116:387-411 (1994) [PubMed] [Gogle Scholar]

9. K. Verschueren, A. Marcoen, V. Schoefs, The internal working model of the self, attachment, and competence in five-year-olds. Child Development. 67:2493-2511 (1996) [PubMed] [Google Scholar].

10. L.A. Sroufe, D. Jacobvitz, S. Mangelsdorf, E. DeAngelo, M.J. Ward, Generational boundary dissolution between mothers and their preschool children: A relationship systems approach. Child Development. 56:317-325 (1985) [PubMed] [Google Scholar]

11. A.B. Doyle, D. Markiewicz, M. Brendgen, M. Lieberman, K. Voss, Mother and father attachment style and marital quality as predictors of child attachment security and selfconcept. Merrill-Palmer Quarterly. 46:514-539 (2000) [Google Scholar]

12. G. Kochanska, Emotional development in children with different attachment histories: The first three years. Child Development. 72:474-490 (2001) [PubMed] [Google Scholar].

13. J. Cassidy, Child-mother attachment and the self in 6-year-olds. Child Development. 59:121134 (1988) [PubMed] [Google Scholar] 
14. R.A. Moroz, Psykholohichnyi fenomen identychnosti osobystosti: katehorialne vyznachennia. Naukovyi visnyk Mykolaivskoho derzhavnoho universytetu imeni V.O. Sukhomlynskoho: Zbirnyk naukovykh prats. Seriia «Psykholohichni nauky». T. 2. Vyp. 4. Mykolaiv: TOV firma «Illion», 159-164 (2010)

15. W. Damon, D. Hart, The development of self-understanding through infancy and adolescence. Child Development. 53:841-864 (1982) [Google Scholar]

16. R.A. Eder, Uncovering children's psychological selves: Individual and developmental differences. Child Development. 61:849-863 (1990) [PubMed] [Google Scholar]

17. H.W. Marsh, R. Debus, L. Bornholt, Validating young children's self-concept responses: Methodological ways and means to understand their responses. In: Teti DM, editor. Handbook of research methods in developmental science. Oxford, England: Blackwell; 138-160 (2004) [Google Scholar]

18. H.W. Marsh, L.A. Ellis, R.G. Craven, How do preschool children feel about themselves? Unraveling measurement and multidimensional self-concept structure. Developmental Psychology. 38:376-393 (2002) [PubMed] [Google Scholar]

19. G.L. Brown, S.C. Mangelsdorf, J.M. Agathen, R.M. Ho, Young children's psychological selves: Convergence with maternal reports of child personality. Social Development (2008) [Google Scholar]

20. D.W. Winnicott, Babies their Mathers. London: Free Associating Books; Reading, Mass.: Addison-Wesley. Perseus Press (1990) 